\title{
Homens podem ser feministas? O pioneirismo dos estudos de masculinidades no Nordeste do Brasil
}

\author{
Can men be feminist? Pioneer masculinity studies in \\ Northeaster Brazil
}

\author{
Mayanne Julia Tomaz FREITAS 1 \\ Jeane FELIX ${ }^{2}$ \\ Maria Eulina Pessoa de CARVALHO
}

\begin{abstract}
Resumo
Este texto explora a trajetória de homens feministas e sua identificação com os estudos de gênero e o movimento feminista, a partir de pesquisa bibliográfica e empírica. Nessa direção, assinala o surgimento dos estudos de masculinidades e a possibilidade de uma identidade feminista de sujeitos homens. Para ilustrar a inclusão dos homens no movimento feminista, foram entrevistados dois fundadores de duas instituiçôes pioneiras nesses estudos no Brasil: uma ONG e um núcleo de uma universidade. Os entrevistados visualizam o movimento feminista como um projeto político coletivo e confirmam a importância do engajamento dos homens na luta pela equidade de gênero.
\end{abstract}

Palavras-chave: Identidade Feminista. Homens Feministas. Estudos de Masculinidades.
Abstract

Based on bibliographical and empirical resear$\mathrm{ch}$, this text explores the trajectories of feminist men and their identification with gender studies and the feminist movement. Towards this aim, it points out the emergence of masculinity studies and the possibility of a male feminist identity. To illustrate the inclusion of men in the feminist movement, interviews were conducted with two founders of two pioneer institutions in masculinity studies: an NGO and a university center. The interviewees envision the feminist movement as a collective political project and confirm the importance of engaging men in the struggle for gender equity.

Keywords: Feminist Identity. Feminist Men. Masculinity Studies.

1 Mestranda do Programa de Pós-graduação em Educação (PPGE), membro do Núcleo Interdisciplinar de Pesquisa e Ação sobre Mulher e Relaçôes de Sexo e Gênero (NIPAM) da Universidade Federal da Paraíba. Campus I - Castelo Branco - João Pessoa, Paraíba, Cep: 58051-900. Tel: 8332881146. E-mail: mayannetomaz51@gmail.com

2 Professora do Departamento de Habilitaçôes Pedagógicas, do Curso de Pedagogia e do Programa de Pósgraduação em Educação (PPGE), membro do Núcleo Interdisciplinar de Pesquisa e Ação sobre Mulher e Relaçóes de Sexo e Gênero (NIPAM) da Universidade Federal da Paraíba. Campus I - Castelo Branco - João Pessoa, Paraíba, Cep: 58051-900. Tel: 8332167448. E-mail: jeanefelix@gmail.com

3 Professora do Departamento de Habilitaçôes Pedagógicas, do Curso de Pedagogia e do Programa de Pósgraduação em Educação (PPGE), membro do Núcleo Interdisciplinar de Pesquisa e Ação sobre Mulher e Relaçôes de Sexo e Gênero (NIPAM) da Universidade Federal da Parába. Bolsista de Produtividade CNPq. Campus I - Castelo Branco - João Pessoa, Paraíba, Cep: 58051-900. Tel: 8332167448. E-mail: mepcarv@gmail.com

R. Educ. Públ.

Cuiabá

v. 27

n. 66

p. $861-881$

set./dez. 2018 


\section{Introdução}

Este texto resulta de uma pesquisa mais abrangente(CARVALHO,2015), que estudou a trajetória dos núcleos da Rede Feminista Norte e Nordeste de Estudos e Pesquisas sobre a Mulher e Relaçôes de Gênero (REDOR), e de um trabalho de conclusão do curso de Pedagogia (FREITAS), que investigou construção da identidade feminista, destacando sujeitos homens de um núcleo de estudos articulados a essa rede. Tem como objetivo explorar a trajetória de homens feministas e sua identificação com os estudos de gênero e o movimento feminista, a partir de pesquisa bibliográfica e empírica. Nessa direção, assinala o surgimento dos estudos de masculinidades e a possibilidade de uma identidade feminista de sujeitos homens.

O levantamento bibliográfico foi realizado em duas etapas: a primeira, nas cinco páginas iniciais do buscador Google e de sua versão acadêmica (Google Acadêmico) com as palavras-chave identidade feminista de homens, homens e identidade feminista e homens feministas; e a segunda, na Revista Estudos Feministas (REF) e na Revista Brasileira de Educação (RBE), entre os anos de 2013 e meados de 2018; nas 11 últimas Reunióes da Associação Nacional de PósGraduação e Pesquisa em Educação (ANPED), tempo de existência do GT 23 - Gênero, sexualidade e educação; e nos Grupos de Trabalhos (GT) e Simpósios Temáticos (ST) que enfocavam gênero da Associação Nacional de Pós-Graduação e Pesquisa em Ciências Sociais (ANPOCS). Além disso, foram feitas entrevistas, em 2015 e 2016, com dois dos fundadores de uma ONG e de um núcleo de pesquisa de uma instituição federal de educação superior do Nordeste.

Os núcleos de estudos de gênero em universidades foram fundados por acadêmicas feministas, comprometidas com a superação das desigualdades de gênero e da subalternidade das mulheres e de sujeitos LGBTQI (lésbicas, gays, bissexuais, travestis, transexuais, queer e intersexo), e assumem, portanto, uma identidade feminista. Inicialmente, esses sujeitos eram mulheres, mas posteriormente surgiram também homens feministas.

O texto foi organizado em três partes complementares, a saber: a primeira aponta o conceito de gênero e traz um breve histórico do movimento feminista até a entrada dos homens na tentativa de problematizar se, de fato, os homens poderiam ou náo ser considerados feministas; a segunda expóe os estudos dos homens e das masculinidades, como uma vertente mais recente dos estudos de gênero e também controversa do feminismo; por fim, a terceira apresenta os estudos de masculinidade no Nordeste brasileiro, a partir das contribuiçóes dos dois homens feministas que foram sujeitos desta pesquisa. 


\section{Homens podem ser feministas?}

O feminismo é um movimento social, teórico e político, que busca a igualdade - legal, social, cultural - entre mulheres e homens (LORBER, 2010). Parte do pressuposto de que vivemos em uma sociedade gendrada, que, entre outras coisas, atribui às mulheres os lugares de menor prestígio em suas diversas esferas e naturaliza o lugar dos homens (particularmente os homens brancos e heterossexuais) nas posiçóes estratégicas de liderança e tomada de decisão. Surge como um movimento de mulheres que busca transformar as relações de dominação de gênero:

O feminismo aparece como um movimento libertário, que não quer só espaço para a mulher - no trabalho, na vida pública, na educação -, mas que luta, sim, por uma nova forma de relacionamento entre homens e mulheres, em que estas últimas tenham liberdade e autonomia para decidir sobre sua vida e seu corpo. (PINTO, 2010, p.16).

Para Alves e Pitanguy (2005), o feminismo busca, em suas práticas, a superação das formas de organização social tradicionais permeadas pela assimetria e pelo autoritarismo. É um movimento de lutas e estratégias que estão em constante processo de re-criação, produzindo sua própria reflexão crítica e sua teoria, estabelecendo-se a partir das resistências, derrotas e conquistas que constituem a história das mulheres.

No contexto teórico, na segunda metade do século XX, gênero surge como o conceito operativo central desse movimento, que gerou um campo de estudos próprio. Para Carvalho e Rabay (2015, p. 121-122), gênero é entendido como uma "[...] construção social e cultural, estrutura e relação de desigualdade, marcador de identidade dominante/dominada, subjetividade.” Louro (1997) lembra que gênero deve ser pensado como relacional e utilizado para referirse tanto às relaçóes entre mulheres e homens, quanto entre homens e homens, e mulheres e mulheres, as quais são estruturadas a partir de características de masculinidade e feminilidade. É um conceito que necessita ser refletido em uma configuração plural e interseccional, considerando sociedades, momentos históricos e os grupos étnicos, religiosos, de classe e geracionais, portanto, devem ser evitadas afirmaçóes generalizantes a respeito de mulheres e homens. Enfim, é um conceito importante, que atravessa todas as áreas de conhecimento, além de políticas e práticas sociais, destacando-se a educação, área onde se situam as autoras deste texto, por meio da qual se dá a reprodução social (BOURDIEU; 
PASSERON, 1977) e se ensinam os lugares culturalmente atribuídos aos sujeitos masculinos e femininos.

Assim, os estudos feministas e de gênero, desenvolvidos por acadêmicas feministas, articulam reflexão teórica e ativismo político, no sentido de modificar as relaçóes sociais e de produção acadêmica, afirmando as mulheres, em suas diferenças, como sujeitos políticos e de conhecimento. Para Zirbel (2007, p.18), esses estudos "[...] questionam os paradigmas das ciências e as definiçóes tradicionais de sociedade, política, público, privado, autonomia, liberdade etc."

A entrada das feministas na academia ocasionou a criaçáo de grupos de pesquisa engajados na construção de teorias e práticas críticas, inicialmente, de interesse das mulheres e, posteriormente, solidárias a outros sujeitos subalternos, considerando a intersecção entre gênero e outros marcadores sociais, tais como raça, classe e geração, na direçẫo da institucionalização da perspectiva feminista. No Brasil, isso se dá a partir da década de 1980. Blay (2006, p. 63) destaca que "[...] a criação dos núcleos de estudos de gênero foi uma estratégia feminista para superar os entraves que as universidades faziam à entrada do tema mulher na academia."

Esses núcleos e grupos de estudo exercem uma função de grande relevância social, pois são transformadores da cultura androcêntrica, machista e patriarcal dentro e fora das instituições de educação superior. Atuam no ensino, pesquisa e extensão, desenvolvem projetos educativos e de intervenção social em parceria com organizações não governamentais (ONG), escolas e associações locais, além de influenciar e informar as políticas públicas. Sua ação política, formativa e de produção de conhecimento potencializa-se na articulação em redes, a exemplo da Rede Feminista Norte e Nordeste de Estudos e Pesquisa sobre a Mulher e Relaçóes de Gênero (REDOR), fundada em 1992 (FREITAS; CARVALHO, 2015). No âmbito da REDOR, há apenas um núcleo formado por homens acadêmicos feministas, dedicado aos estudos dos homens e masculinidades, criado em 1998 (FREITAS, 2016).

Os grupos feministas, conforme indicado anteriormente, foram, de início, compostos apenas por mulheres, sendo relativamente recentes tanto a incorporação de homens quanto os estudos sobre as masculinidades. Há, no âmbito dos movimentos feministas, um debate acerca da possibilidade e da legitimidade de homens serem ou não feministas. Por um lado, advoga-se que apenas os sujeitos que vivenciam diretamente os efeitos do machismo (ou seja, as mulheres) podem se identificar como feministas; por outro lado, argumenta-se que o feminismo, como movimento que luta pelo enfrentamento das desigualdades de gênero, deve, também, incorporar os homens, seja porque o machismo traz efeitos negativos para toda a sociedade, incluindo os próprios homens, seja porque só poderia ser efetivamente erradicado com a participação deles. Não é nosso foco, neste texto, 
explorar esse debate, todavia, acreditamos na importância do engajamento de homens na construção de masculinidades não violentas e de uma sociedade mais justa no âmbito das relaçóes de gênero e defendemos a importância de homens que se identificam como feministas nessa construção.

Castells (1999) explica a identidade a partir dos atores sociais como um processo de construção de significados, baseado em características culturais, com a possibilidade de haver identidades múltiplas para um determinado indivíduo ou ator coletivo. Essa pluralidade ocasiona contradiçóes na autorrepresentaçáo e na ação social, o que requer definição da relação entre identidade e papel. Os papeis são determinados por normas estruturadas pelas instituiçóes e organizaçóes da sociedade e determinam as identidades. Por outro lado, as identidades sáo mais compostas de significados do que os papeis. As identidades organizam significados, enquanto os papeis organizam funções.

Segundo Castells (1999, p. 23), “[...] toda e qualquer identidade é construída”. A construçáo social da identidade sempre ocorre em um contexto marcado por relaçôes de poder, assim ele propóe três formas de origem da construção de identidades: identidade legitimadora, identidade de resistência e identidade de projeto. Essa construção desenvolve-se numa sequência: da identidade de resistência, quando atores se encontram em posiçôes/condições desvalorizadas e/ ou estigmatizadas, para a identidade de projeto, que almeja uma nova identidade capaz de redefinir sua posição na sociedade e, por fim, legitimar-se, quando passa a expandir e racionalizar sua dominação, alcançando a identidade legitimadora.

No caso da identidade feminista, de acordo com Morais (2016), ela foi e é construída a partir do reconhecimento das desigualdades de gênero e das estratégias utilizadas para o seu enfrentamento. Portanto, a identidade feminista, individual e coletiva, é tanto identidade de resistência às desigualdades de gênero e à dominação masculina, quanto identidade de projeto: de um mundo com igualdade e justiça de gênero para todas e todos. Esse é o projeto do feminismo como movimento social e campo de teorizaçâo.

Para Velasco-Martinez (2016), a identidade feminista, como qualquer identidade social, deriva da consciência de pertencer e sentir-se parte de um coletivo que compartilha, entre seus membros, ideais, valores, comportamentos, reconhecimento e solidariedade. Por conseguinte, tanto as mulheres quanto os homens podem compartilhar uma identidade coletiva feminista. Embora o sujeito feminista historicamente seja a mulher, ou melhor, as mulheres em suas diversas e múltiplas identidades, o feminismo é para todos e todas, como diz Bell Hooks (2000), e interessa também aos homens, uma vez que eles também sáo sujeitos de gênero, ocupando essa posição, em geral, como opressores. Contudo, sem uma educação feminista que transforme os homens, as relaçôes de desigualdade não 
mudarão. Nessa perspectiva, se pode pensar (e é desejável construir) a identidade feminista de homens.

\section{Estudos dos homens e masculinidades}

Anteriormente, muitos trabalhos se autodenominavam como estudos de gênero quando, na realidade, se restringiam às pesquisas sobre a mulher e a condição feminina, deixando lacunas com relação a análises inter e intragêneros. Os estudos sobre homens e masculinidades ganham impulso a partir da maturação dos estudos de gênero. Inicialmente só era possível aprofundar tais estudos por meio da literatura anglo-saxônica ou norte-americana, os chamados men 's studies (HEILBORN; CARRARA, 1998).

Segundo Medrado e Lyra (2008), os estudos sobre masculinidades ainda são pouco desenvolvidos quando comparados com os estudos de gênero, feminismo e teoria queer. No Brasil, o interesse nos estudos sobre homens e masculinidades surge por intermédio de uma agenda política internacional, que foi pautando os temas que deveriam ter investimentos políticos e acadêmicos, tais como o HIV/Aids. Os homens passam a ser pesquisados no início da década de 1990, em meio a grandes conferências internacionais em que se discutiam direitos das mulheres, nascendo a necessidade da inclusão dos homens nas políticas voltadas à equidade de gênero. Tais conferências iam além dos interesses das mulheres, pois também tratavam de temas relacionados a diretos humanos, população, meio ambiente e controle da difusão da epidemia de HIV/Aids. Esse último enfocava necessariamente açóes sobre os homens, na medida em que eles representavam, naquele momento, o maior número de infecçóes, surgindo o empenho em financiamento de pesquisas e intervençôes em prol da população masculina (HEILBORN; CARRARA, 1998).

Segundo Connell (1995), a masculinidade só existe em contraste com a feminilidade, já que ambas são construçôes sociais e relacionais. Esse contraste é explicado por Silva (2008) mediante o conceito de representaçáo, numa perspectiva pós-estruturalista, entendida como "um sistema linguístico e cultural: arbitrário, indeterminado e estreitamente ligado a relaçóes de poder.” (p. 91). A representação é o canal pelo qual a identidade e a diferença vinculam-se a sistemas de poder, os quais, por meio da representação, definem e determinam as identidades.

Ribeiro e Siqueira (2005) ressaltam que o termo masculinidade deve ser tratado no plural, superando-se o binarismo e destacando as diversas possibilidades de viver a masculinidade, assim como a feminilidade. Pesquisadores/as dos estudos 
de gênero utilizam dois termos para definir as masculinidades ocidentais: a masculinidade hegemônica ou dominante, referente à posição dos homens brancos, ocidentais e heterossexuais, definida pela capacidade para o trabalho, força física e potência sexual; e a masculinidade subalterna ou marginal, referente aos homossexuais e homens que não se encaixam no modelo hegemônico (RIBEIRO; SIQUEIRA, 2005). Os estudos de gênero sugerem também que se analisem as diferentes hierarquias sociais de gênero, classe, raça e geraçáo (HEILBORN; CARRARA, 1998), que se dão entre homens e mulheres, mas também entre homens e homens, mulheres e mulheres.

No âmbito do levantamento bibliográfico realizado para compor este artigo foram identificados apenas três trabalhos, sendo duas dissertaçóes e um artigo, com as palavras-chave homens feministas. Os demais trabalhos encontrados nessa busca tratavam dos estudos de homens e masculinidades. Cabe destacar, todavia, que mesmo os estudos e pesquisas sobre homens e masculinidades ainda são incipientes em nosso país. Assim, consideramos neste levantamento os textos que mencionavam os estudos de homens e masculinidades e não apenas aqueles que tratavam diretamente de homens feministas.

Nas últimas 11 Reuniōes da ANPED, no GT 23 - Gênero, Sexualidade e Educação, encontramos apenas 15 trabalhos que focalizavam os homens como sujeitos: Brito (2004); Pincinato (2004); Ribeiro e Siqueira (2005); Cardoso (2007); Bandeira (2009); Andreoli (2010); Rosa (2010); Correia (2010); Machado e Lima (2011); Menezes (2011); Brito (2011); Ritti (2012); Damico (2012); Monteiro e Altmann (2013); Silva Júnior e Ivenick (2017). Nas Reunióes da ANPOCS, nos GT e ST que tinham como foco gênero, foram encontrados 10 trabalhos: Sousa (2001); Tarnowski (2001); Batista e Lopes (2004); Fernandes (2007); Araújo (2010); Rego (2014); Sorj, Daflon e Grillo (2017); Sartor (2018); Silva (2018); Teixeira (2018).

Na Revista Brasileira de Educação, no período de 2013 até meados de 2018, foi encontrado apenas o texto de Marchi e Santos (2017) com as palavras-chave que exploramos.

$\mathrm{Na}$ Revista Estudos Feministas, categorizada como interdisciplinar, nesse mesmo período, foram encontrados oito artigos, sendo sete publicados em um mesmo número: Lago e Wolff (2013); Connel e Messerschmidt (2013); Bermúdez (2013); Misckolci (2013); Rolim e Rodrigues (2013); Alós (2013); Figeroa-Perea (2013); Hooks (2015), dos quais quatro são de pesquisadores estrangeiros; além de seis resenhas: Andreta (2014); Corseuil (2014); Veras (2014); Silva (2015); Witmann (2016); Franco (2016).

O levantamento no Google e Google Acadêmico identificou duas dissertaçóes e um artigo publicado em periódico. A primeira dissertação, intitulada Narrativas 
feministas de homens portugueses (MATIAS, 2008), desenvolvida no Mestrado em Psicologia Comunitária do Instituto Superior de Psicologia Aplicada, em Portugal, resultou de uma pesquisa narrativa biográfica realizada com 10 homens que se afirmavam feministas. $\mathrm{O}$ autor propóe a produçáo de uma literatura que aponte para os homens os benefícios que eles terão, pois o feminismo é bom para todos. A segunda dissertação, intitulada Homens Feministas: A emergência de um sujeito politico entre fronteiras contingentes (FERREIRA, 2012), defendida no Mestrado em Sociologia da Universidade Federal de Pernambuco, foi desenvolvida a partir de entrevistas com homens participantes de uma ONG feminista. Assinala que os homens compreendem a reivindicação por uma identidade política feminista como fruto do progresso do feminismo e apresenta a concepção dos entrevistados sobre ser um homem feminista ou um homem pró-feminismo. Segundo a autora, para os homens entrevistados o termo "pró-feminista mantém um distanciamento dos homens em relação ao feminismo, ou seja, ser pró-feminista é estar, mesmo que estabelecendo uma relação de proximidade, fora do movimento"; já os homens feministas seriam aqueles "que se reafirmam como parte integrante do feminismo em oposição àqueles que, apesar do apoio, acham-se fora." (FERREIRA, 2012, p. 86). Por sua vez, o artigo sobre homens feministas, desenvolvido a partir da análise de comentários de uma rede social, buscou apresentar os limites da associação dos homens ao movimento, destacando o protagonismo das mulheres (CASTRO; COURA; LINS, 2018).

\section{Estudos de masculinidades no nordeste brasileiro: contribuições de dois homens feministas}

Como referido, os estudos sobre masculinidades no Brasil, e especialmente no Nordeste, ainda são recentes e incipientes. Para ilustrar, cabe mencionar que, no âmbito da REDOR, o GT Homens e Masculinidades foi introduzido apenas no ano 2012, no $1^{\circ}$ Encontro da REDOR, organizado pelo Núcleo Interdisciplinar de Pesquisa e Ação sobre Mulher e Relações de Sexo e Gênero (NIPAM), na Universidade Federal da Paraíba (UFPB).

Os dois pesquisadores que foram entrevistados para este texto contribuem significativamente para a produção acadêmica e a atuação política sobre esses temas, como apresentamos a seguir. Denominados neste texto de Homem Feminista 1 (HF1) e Homem Feminista $2(\mathrm{HF} 2)^{4}$, participaram da construção

4 A pedido dos entrevistados omitimos seus nomes, bem como os das instituiçóes às quais se vinculam. 
de uma ONG e de um grupo de estudos de gênero com foco em masculinidades. Assim, articulam, ao mesmo tempo, militância no campo dos movimentos sociais e realização de projetos sociais à formação e à pesquisa, no âmbito acadêmico. Em suas trajetórias de ativismo político e inserção acadêmica, HF1 e HF2 constroem sua identificação feminista, como será ilustrado a seguir.

\section{Identificação feminista}

De acordo com Morais (2016), no movimento feminista existem várias identidades e essas são autoconstruídas e coletivas. A identidade feminista foi construída em oposição a uma identidade sexista/machista e às normas e valores androcêntricos, aos privilégios masculinos. Contudo, existem homens que reconhecem e valorizam as lutas das mulheres, particularmente aquelas contra as desigualdades de gênero. Dessa forma, HF1 considera-se um homem feminista, pois acredita no feminismo como projeto de sociedade:

Sim, sou um homem feminista, pois entendo o feminismo como um projeto de sociedade, como uma proposta de relaçóes sociais entre as pessoas. (HF1, entrevista, 2015).

O feminismo é um movimento que busca enfrentar as desigualdades de gênero, problematizando a cultura sexista e androcêntrica; logo, o reconhecimento e o engajamento de homens no feminismo constituem uma aposta políticopedagógica por um mundo mais justo, na medida em que a transformação cultural só ocorrerá efetivamente quando os homens deixarem a posição de opressores. Além disso, é importante sinalizar que o machismo também está presente no comportamento de muitas mulheres, que foram ensinadas a naturalizar a dominação masculina. Nesse sentido, pensar (e fazer) o feminismo como um projeto de sociedade demanda envolvimento de homens e mulheres.

Em relaçáo à mesma pergunta, HF2 hesitou inicialmente em se afirmar homem feminista, em meio às discussóes sobre homens pró-feministas anteriormente sinalizadas. Entretanto, atualmente, considera-se um homem feminista por também acreditar no feminismo como um projeto político, um feminismo crítico e reflexivo:

Sim. Demorei um pouco para dizer isso a mim mesmo [...] Eu entendo o feminismo como um projeto político. Não como uma identidade biológica ou uma identidade restrita à experiência. A experiência é fundamental, mas a experiência pode gerar 
alienação, não necessariamente gerar a reflexão crítica. Então eu penso a experiência, a partir da discussáo feminista, como um espaço de reflexão crítica, da reflexividade. Nesse sentido, não vejo problema nenhum em me dizer homem feminista. (HF2, entrevista, 2016).

Sobre a identificação como homem feminista, HF2 também reitera o feminismo como um projeto político e de sociedade. Tal perspectiva, em nossa análise, faz sentido porque o feminismo é tanto um projeto coletivo quanto um movimento de engajamentos pessoais. $\mathrm{O}$ engajamento feminista pode ser considerado uma escolha pessoal, todavia, uma escolha pessoal é sempre uma escolha política que póe em circulação formas de ser e estar no mundo que podem contribuir para transformar ou reforçar posiçóes. Assim, os movimentos sociais nos quais nos engajamos, as pesquisas que realizamos, as identidades que assumimos representam sempre nossas escolhas pessoais e políticas, como ressalta Louro (2007, p. 213):

O modo como pesquisamos e, portanto, o modo como conhecemos e também como escrevemos é marcado por nossas escolhas teóricas e por nossas escolhas políticas e afetivas. É, certamente, afetado por nossa história pessoal, pelas posiçóes-de-sujeito que ocupamos, pelas oportunidades e encontros que tivemos e temos.

Todavia, mesmo que assumam a identidade de homens feministas, nossos entrevistados fazem questão de legitimar as mulheres como protagonistas do movimento, conforme expressa HF1:

Faço questão de reconhecer e de me nomear que sou sim feminista e quando digo isso também náo estou negando o processo e a legitimidade do sujeito político do feminismo, que são as mulheres. Mas considero que sim, é possivel pensarmos em conjunto, homens e mulheres, o que significa ser feminista e fazer proposiçôes feministas. (HF1, entrevista, 2015).

Além de enfatizar o protagonismo das mulheres no movimento feminista, HF1 também acredita que as reflexóes críticas feitas sobre os homens e as masculinidades só ocorreram em razão da transformação da condição feminina, que é efeito da luta do movimento, visto que tais reflexóes não partiram particularmente dos homens. Cabe lembrar que o feminismo é um movimento, desde sua origem, protagonizado por mulheres, já que são elas os sujeitos mais 
atingidos pelas opressóes de gênero. Um exemplo desse protagonismo é a própria adoção e utilização do conceito de gênero como ferramenta política, pedagógica e analítica do feminismo.

Ressignificado pelas teóricas e estudiosas feministas, o conceito de gênero tem sido utilizado desde a década de 1970 para problematizar as desigualdades entre homens e mulheres desnaturalizando as diferenças historicamente construídas que sustentam o patriarcado. Esse conceito, todavia, não foi devidamente senso comunizado, conforme apontam Carvalho e Rabay (2015). Pelo contrário, ele tem sido apropriado, mais recentemente, por grupos conservadores, que vêm atacando a ideologia de gênero, com intuito de invisibilizar as lutas feministas. Em virtude disso, o conceito de gênero passa a ser ainda mais valioso e precisa ser cada vez mais disseminado e defendido, por mulheres e homens. $\mathrm{O}$ feminismo, nessa direção, precisa apostar também nos estudos e práticas com (e sobre) homens e masculinidades.

Em relação à inserção dos homens no feminismo, indica HF1:

Não considero que o feminismo seja algo apenas das mulheres, mesmo que reconhę̧a - e faço questão disso: de reconhecer que a autoria das reflexóes críticas que fazemos com e sobre os homens e as masculinidades foi em função das proposiçôes de transformaçâa da condiçâa feminina realizadas pelo movimento de mulheres e pelo movimento feminista. Ou seja, as discussöes e propostas de ação que fazemos não tiveram origem em açôes feitas pelos homens. Com excęâa do debate sobre sexualidade proposto pelos homens homossexuais, nós não temos exemplos de articulação de homens tentando transformar sua condição de existência, transformar a nossa cultura machista, patriarcal e conservadora. (HF1, entrevista, 2015).

HF2 expóe sua concepção sobre o movimento feminista e apresenta opinióes semelhantes as de HF1 sobre o surgimento das reflexóes sobre homens e masculinidades a partir desse movimento.

O movimento feminista é um movimento que propóe um reordenamento social de vários niveis da produção do conhecimento, da vida privada e pública, da ciência, ou seja, um movimento que busca uma reconstrução das instituiçôes a partir de um olhar voltado para a equidade de direitos entre homens e mulheres e uma quebra nessa ideia de masculinidade e feminilidade como oposiçôes e dicotomias pré-estabelecidas e pré-discursivas. (HF2, entrevista, 2016). 
HF1 e HF2 têm concepçóes semelhantes a respeito do protagonismo das mulheres na teorizaçáo feminista e sobre ela ter sido o ponto de partida dos estudos dos homens e das masculinidades. O reconhecimento dos estudos sobre as mulheres como anteriores aos estudos sobre os homens desloca uma posição social tradicionalmente cristalizada, qual seja: os homens, seus estudos, sua produção científica, sempre estão em primeiro lugar. Contudo, cabe reconhecer também que os estudos de gênero e feministas ainda são considerados estudos de menor valor no âmbito da ciência e que padecem de baixo reconhecimento e legitimidade na academia (MORAIS; CARVALHO, 2015).

Nossos entrevistados reconhecem as mulheres como $o$ sujeito político do feminismo, mas consideram que os homens também podem, com elas, pensar criticamente sobre as relaçóes sociais de gênero e fazer proposiçóes feministas. Ambos pensam o feminismo como projeto de sociedade ou projeto político de construção coletiva por mulheres e homens. Assim, seus trabalhos ultrapassam os muros da universidade. Essa perspectiva é fundamental para a construção de uma sociedade mais justa. Ora, se convivemos, mulheres e homens, nos mesmos espaços sociais, precisamos fazer com que esses espaços sejam ocupados equanimemente.

\section{Considerações finais}

O feminismo, como movimento social, teórico e político, ganha espaço na academia por meio dos núcleos e grupos de estudos de gênero nas décadas finais do século XX no Brasil. Nesse contexto, surgem uma ONG e um núcleo de estudos pioneiros no estudo dos homens e das masculinidades na perspectiva do feminismo no Nordeste do Brasil. Dentre seus fundadores, HF1 e HF2 ilustram a identidade feminista de homens comprometidos com a superação das desigualdades de gênero, mesmo reconhecendo as mulheres como protagonistas do feminismo. Ambos se afirmam homens feministas, cujas identificações com o feminismo são construídas ao longo de sua formação e carreira acadêmica, associadas ao ativismo político em prol da transformação simbólica e prática das formas de masculinidade machista e patriarcal que têm posicionado homens e mulheres em diferentes espaços sociais.

Vale salientar que ainda se conta com um pequeno número de homens engajados em açóes culturais e educativas da agenda feminista. Recentemente, em 2014, surgiu um movimento que convida os homens a se engajarem na luta para modificar as práticas machistas e violentas: a Campanha ElesPorElas (HeForShe), lançada pela ONU Mulheres, a entidade das Naçóes Unidas para a igualdade de gênero e o empoderamento das mulheres. Trata-se de uma campanha global 
visando envolver homens e meninos na superação dos obstáculos sociais e culturais que impedem as mulheres de atingir seu potencial, e ajudar homens e mulheres a criarem, juntos, uma nova ordem social (<http://www.onumulheres. org.br/elesporelas/>), o que supóe a redefinição das masculinidades, sobretudo a extinção das formas de masculinidade violenta.

A chegada desses novos integrantes no movimento feminista é de grande importância, pois só ocorrerá mudança na ordem patriarcal quando os homens saírem da posição de opressores das mulheres e reconhecerem os direitos humanos delas; quando aproveitarem suas posiçóes de influência e liderança para criar políticas públicas de equidade de gênero; quando assumirem a disposiçáo de abrir mão de seus privilégios e lutar pela transformação da cultura androcêntrica; quando passarem a lutar também em prol do desenvolvimento e realização pessoal das mulheres próximas e distantes; quando decidirem por um fim à violência de gênero, que não afeta apenas as mulheres, mas os afeta também.

Enfim, este trabalho intentou trazer uma reflexão sobre as contribuiçóes desejáveis e promissoras da construção de uma identidade feminista de homens, ilustrando a possibilidade da promoçáo de uma cultura de igualdade de gênero a partir do aporte dos homens. Trouxe como exemplo o engajamento de dois homens ativistas e acadêmicos que assumem concretamente essa identidade, buscando contribuir com uma sociedade mais justa e menos desigual para homens e mulheres. A partir do levantamento da produção brasileira sobre o tema, espera estimular novos trabalhos, sobretudo no campo da educação.

\section{Referências}

ALÓS, A. P. Não contar a ninguém ou contar a todo mundo? Colapsos da masculinidade em No se lo digas a nadie. Revista Estudos Feministas, Florianópolis, v. 21, n. 1, p. 343-370, maio 2013. ISSN 1806-9584. Disponível em: <https://periodicos.ufsc.br/index.php/ref/article/view/S0104026X2013000100018/24654>. Acesso em: 17 abr. 2016.

ALVES, B. M.; PITANGUY, J. O que é Feminismo. Brasília, DF: Brasiliense, 2005. (Coleção Primeiros Passos).

ANDRETA, B. L. Masculinidades subversivas nos romances de Manuel Puig, Caio Fernando Abreu e Jaime Bayly. Revista Estudos Feministas, Florianópolis, v. 22, n. 1, p. 364-368, maio 2014. ISSN 1806-9584. Disponível em: <https://periodicos.ufsc.br/index.php/ref/article/view/S0104026X2014000100021/26817>. Acesso em: 17 abr. 2016. 
ANDREOLI, G. S. O bailarino self-made: trajetórias do masculino na dança. In: REUNIÃO NACIONAL DA ANPED, 33., 2010, Caxambu/MG. Anais... Caxambu, 2010. Disponível em: <http://33reuniao.anped.org.br/33encontro/ app/webroot/files/file/Trabalhos\%20em\%20PDF/GT23-6439--Int.pdf >. Acesso em: 05 abr. 2016.

ARAUJO, E. C. de. As estratégias masculinas ao lidar com a dor da traição: associações de cornos, criação de aforismos e sociabilidade em mesa de bar. In: ENCONTRO ANUAL ANPOCS, 34., 2010, Caxambu/MG. Anais... Caxambu, 2010. Disponível em: <http://www.anpocs.com/index.php/ papers-34-encontro/st-8/st30-2/1644-earaujo-as-estrategias/file>. Acesso em: 05 jul. 2018.

BANDEIRA, G. A. Um currículo de masculinidades nos estádios de futebol. In: REUNIÃO NACIONAL DA ANPED, 32., 2009, Caxambu/MG. Anais... Caxambu, 2009. Disponível em: <http://32reuniao.anped.org.br/arquivos/ trabalhos/GT23-5384--Int.pdf>. Acesso em: 05 abr. 2016.

BATISTA, A. B.; LOPES, M. de F. Gênero e masculinidade: construção de um ethos militar. In: ENCONTRO ANUAL ANPOCS, 28., 2004, Caxambu/ MG. Anais... Caxambu, 2004. Disponível em: <http://www.anpocs.com/index. php/28d-encontro-anual-2004/1043-encontros-anuais/28o-encontro/546programa-e-resumos>. Acesso em: 05 jul. 2018.

BERMÚDEZ, M. de M. Connel y el concepto de masculinidades hegemónicas: notas críticas desde la obra de Pierre Bourdieu. Revista Estudos Feministas, Florianópolis, v. 21, n. 1, p. 283-300, maio 2013. ISSN 1806-9584. Disponível em: <https://periodicos.ufsc.br/index.php/ref/article/view/S0104026X2013000100015/24651>. Acesso em: 17 abr. 2016.

BLAY, E. A. Núcleos de estudos da Mulher X Academia. In: Brasil/SPM (Org.). Pensando gênero e ciência. Encontro Nacional de Núcleos e Grupos de Pesquisas. 2005/2006. Presidência da República. Brasília, DF: Secretaria Especial de Políticas para as Mulheres, 2006. p. 63-71.

BOURDIEU, P.; PASSERON, J. C. A Reproduçáo: elementos para uma teoria do sistema de ensino. Rio de Janeiro: Francisco Alves, 1977.

BRITO, R. S. Masculinidades e feminilidades: implicaçóes para o fracasso/sucesso escolar de meninos e meninas nas séries iniciais. In: REUNIÃO NACIONAL DA ANPED, 27., 2004, Caxambu/MG. Anais... Caxambu, 2004. Disponível em: <http://27reuniao.anped.org.br/ge23/t2310.pdf>. Acesso em: 05 abr. 2016. 
BRITO, R. S. Gênero, raça, juventude e fracasso escolar: masculinidades nas narrativas juvenis. In: REUNIÃO NACIONAL DA ANPED, 34., 2011, Natal/ RN. Anais... Natal, 2011. Disponível em: <http://34reuniao.anped.org.br/ images/trabalhos/GT23/GT23-599\%20int.pdf>. Acesso em: 05 abr. 2016.

CARVALHO, M. E. P. de. Trajetórias e contribuiçóes dos Núcleos de Estudos da Mulher e Relaçóes de Gênero integrantes da Rede Feminista Norte e Nordeste de Estudos e Pesquisa sobre Mulher e Relaçóes de Gênero - REDOR: do pessoal ao institucional. Relatório do Projeto CNPq/ UFPB. 2015.

CARVALHO, M. E. P. de.; RABAY, G. Usos e incompreensões do conceito de gênero no discurso educacional no Brasil. Estudos Feministas, Florianópolis, v. 23, n. 1, p. 119-136, jan./abr./2015. Disponível em: <https:// periodicos.ufsc.br/ index.php/ref/article/view/37466/28761>. Acesso em: 20 jun. 2017.

CARDOSO, A. F. Homens fora de lugar? A identidade de professores homens na docência com crianças. In: REUNIÂO NACIONAL DA ANPED, 30., 2007, Caxambu/MG. Anais... Caxambu, 2007. Disponível em: <http://30reuniao. anped.org.br/trabalhos/GT23-3550--Int.pdf>. Acesso em: 05 abr. 2016.

CASTELLS, M. O poder da identidade. Tradução de Klauss Brandini Gerhardt. São Paulo: Paz e Terra, 1999.

CASTRO, R. P. de; COURA, A. C. M.; LINS, R. G. Homens no movimento feminista? Problematizaçôes a partir de uma postagem da página não me Khalo no Facebook. Revista Debates Insubmissos, Caruaru, PE. Brasil, v. 1, n. 1, p. 185-210, jan./abr. 2018. Disponível em: <https://periodicos.ufpe.br/revistas/ debatesinsubmissos/article/view/236383/29053>. Acesso em: 01 jul. 2018.

CORSEUIL, A. R. Masculinidades e ressignificaçóes. Revista Estudos Feministas, Florianópolis, v. 22, n. 2, p. 699-701, maio 2014. ISSN 1806-9584. Disponível em: <https://periodicos.ufsc.br/index.php/ref/article/view/36559/28563>. Acesso em: 17 abr. 2016.

CONNELL, R. Masculinities. Cambridge, Polity Press; Sydney, Allen \& Unwin; Berkeley, University of California Press, 1995.

CONNELL, R.; MESSERSCHMIDT, J. W. Masculinidade hegemônica: repensando o conceito. Revista Estudos Feministas, Florianópolis, v. 21, n. 1, p. 241-282, maio 2013. ISSN 1806-9584. Disponível em: <https://periodicos.ufsc. br/index.php/ref/article/view/S0104-026X2013000100014/24650>. Acesso em: 17 abr. 2016. 
CORREIA, V. S. A. A visão androcêntrica do mundo: elemento facilitador para o acesso dos homens às funções da gestão escolar. In: REUNIÃO NACIONAL DA ANPED, 33., 2010, Caxambu/MG. Anais... Caxambu, 2010. Disponível em: <http://33reuniao.anped.org.br/33 encontro/app/webroot/files/file/ Trabalhos\%20em\%20PDF/GT23-6642--Int.pdf>. Acesso em: 05 abr. 2016.

DAMICO, J. G. S. Um bom lugar: constituição de masculinidades juvenis na periferia urbana. In: REUNIÃO NACIONAL DA ANPED, 35., 2012, Porto de Galinhas/PE. Anais... Porto de Galinhas, 2012. Disponível em: <http://35reuniao. anped.org.br/images/stories/trabalhos/GT23\%20Trabalhos/GT23-2344_int. pdf>. Acesso em: 05 abr. 2016.

FERNANDES, L. A. B. Construindo Identidades Sociais: Feminilidade e Masculinidade. In: Encontro Anual ANPOCS, 31., 2007, Caxambu/MG. Anais... Caxambu, 2007. Disponível em: <http://www.anpocs.com/index.php/ papers-31-encontro/st-7/st18-5/2953-luisfernandes-construindo/file>. Acesso em: 05 jul. 2018.

FERREIRA, M. A. de A. Homens Feministas: a emergência de um sujeito político entre fronteiras contingentes. 2012. 94 f. Dissertação (Mestrado em Sociologia) - Centro de Filosofia e Ciências Humanas, Universidade Federal de Pernambuco, Recife. 2012.

FIGUEROA-PEREA, J.-G. Algunas reflexiones sobre el estudio de los hombres desde el feminismo y desde los derechos humanos. Revista Estudos Feministas, Florianópolis, v. 21, n. 1, p. 371-393, maio 2013. ISSN 1806-9584. Disponível em: <https://periodicos.ufsc.br/index.php/ref/article/view/S0104026X2013000100019/24655>. Acesso em: 17 abr. 2016.

FRANCO, N. Gênero e esporte: masculinidades e feminilidades na escola. Revista Estudos Feministas, Florianópolis, v. 24, n. 2, p. 665-668, jun. 2016. ISSN 1806-9584. Disponível em: <https://periodicos.ufsc.br/index.php/ref/ article/view/44617/31767>. Acesso em: 17 abr. 2016.

FREITAS, Mayanne Júlia Tomaz. A construçáo da identidade feminista de homens: um caso pioneiro no Brasil. (Monografia) - Centro de Educaçáo, Universidade Federal da Paraíba, João Pessoa, 2016.

FREITAS, Mayanne Júlia Tomaz. CARVALHO, Maria Eulina Pessoa de. Trajetória dos núcleos de estudos da mulher e relaçóes de gênero integrantes da REDOR. Revista Espaço do Currículo, João Pessoa, v. 8, n. 2, 2015. Disponível em: <http:// periodicos.ufpb.br/ojs/index.php/rec/article/view/rec.2015.v8n2.270279/14122> Acesso em: 01 jun. 2016. 
HEILBORN, M. L.; CARRARA, S. Em Cena, os Homens.... Revista Estudos Feministas, Florianópolis, v. 6, n. 2, p. 370, jan. 1998. ISSN 1806-9584. Disponível em: <https://periodicos.ufsc.br/index.php/ref/article/view/12013>. Acesso em: 17 jul. 2018.

HOOKS, B. Feminism is for Everybody: Passionate politics. Cambridge, MA: South End Press, 2000.

HOOKS, B. Escolarizando homens negros. Revista Estudos Feministas, Florianópolis, v. 23, n. 3, p. 677-689, nov. 2015. ISSN 1806-9584. Disponível em: <https://periodicos.ufsc.br/index.php/ref/article/view/41784/30373>. Acesso em: 17 jul. 2018.

LAGO, M. C. de S.; WOLFF, C. S. Masculinidades, diferenças, hegemonias. Revista Estudos Feministas, Florianópolis, v. 21, n. 1, p. 233-240, maio 2013. ISSN 1806-9584. Disponível em: <https://periodicos.ufsc.br/index.php/ref/ article/view/S0104-026X2013000100013/24649>. Acesso em: 17 abr. 2016.

LORBER, J. Gender inequality: Feminist theories and politics. 4. ed. New York: Oxford University Press, 2010.

LOURO, G. L. Gênero, sexualidade e educação: uma perspectiva pósestruturalista. Petropólis: Vozes, 1997.

LOURO, G. L. Gênero, sexualidade e educação: das afinidades políticas às tensôes teórico-metodológicas. Educaçáo em Revista, n. 46, p. 201-218, dez. 2007. Disponível em: <http:/www.scielo.br/pdf/edur/n46/a08n46>. Acesso em: 03 ago. 2018.

MACHADO, R.; LIMA, R. P. M. O delírio do corpo: derivas das masculinidades. In: Reunião Nacional da ANPED, 34., 2011, Caxambu/MG. Anais... Caxambu, 2011. Disponível em: <http://34reuniao.anped.org.br/images/trabalhos/GT23/ GT23-88\%20int.pdf>. Acesso em: 05 abr. 2016.

MARCHI, R. de C.; SANTOS, T. R. Produção e conservação escolar da masculinidade no romance O Ateneu. Rev. Bras. Educ., Rio de Janeiro, v. 22, n. 68, p. 35-60, mar. 2017. Disponível em: <http://www.scielo.br/scielo. php?script=sci_arttext\&pid=S1413-24782017000100035\&lng=pt\&nrm=iso $>$. Acesso em: 17 jul. 2018.

MATIAS, D. F. M. Narrativas de Homens Feministas Portugueses. 2008. 90 f. Dissertação (Mestrado em Psicologia Comunitária) - Instituto Superior de Psicologia Aplicada, Lisboa, 2008. 
MATIAS, D. F. M. Por uma matriz feminista de gênero para os estudos sobre homens e masculinidades. Estudos Feministas, Florianópolis, v. 16, n. 3, p. 809-840, set./dez. 2008. Disponível: <http://www.scielo.br/pdf/ref/v16n3/05>. Acesso em: 04 jul. 2017.

MENEZES, C. S. de. Distintas masculinidades: consideraçóes sobre a escolarização de alunos da educação de jovens e adultos. In: REUNIÁO NACIONAL DA ANPED, 34., 2011, Caxambu/MG. Anais... Caxambu, 2011. Disponível em: $<$ http://34reuniao.anped.org.br/images/trabalhos/GT23/GT23-171\%20int. pdf>. Acesso em: 05 abr. 2016.

MISKOLCI, R. Machos e Brothers: uma etnografia sobre o armário em relações homoeróticas masculinas criadas on-line. Revista Estudos Feministas, Florianópolis, v. 21, n. 1, p. 301-324, maio 2013. ISSN 1806-9584. Disponível em: <https://periodicos.ufsc.br/index.php/ref/article/view/S0104026X2013000100016/24652>. Acesso em: 17 abr. 2016.

MONTEIRO, M. K.; ALTMAN, H. Trajetórias na docência: professores homens na educação infantil. In: REUNIÃO NACIONAL DA ANPED, 36., 2013, Goiânia/GO. Anais... Goiânia, 2013. Disponível em: <http://36reuniao.anped. org.br/pdfs_trabalhos_aprovados/gt23_trabalhos_pdfs/gt23_2689_texto.pdf>. Acesso em: 05 abr. 2016.

MORAIS, A. B. A. de. Institucionalizaçáo dos Estudos de Gênero na UFMA: Uma análise da identidade feminista a partir da narrativa de vida. 2016. 137 f. Dissertação (Mestrado em Educaçáo) - Centro de Educaçáo, Universidade Federal da Paraíba, João Pessoa, 2016.

MORAIS, A. B. A. de; CARVALHO, M. E. P. De. Institucionalização dos estudos de gênero na universidade: uma análise a partir de narrativas de acadêmicas feministas. Tempos e Espaços em Educaçáo, v. 8, n. 17, p. 235-246, set/dez. 2015. ISSN: 2358-1425. Disponível em: https://seer.ufs.br/index.php/revtee/ article/viewFile/4526/3722. Acesso em: 05 jul. 2018.

PICINATO, D. A. V. História do magistério: experiências masculinas na carreira administrativa no estado de São Paulo (1950-1980). In: REUNIÃO NACIONAL DA ANPED, 27., 2004, Caxambu/MG. Anais... Caxambu, 2004. Disponível em: <http://27reuniao.anped.org.br/ge23/t2310.pdf>. Acesso em: 05 abr. 2016.

PINTO, C. R. J. Feminismo, história e poder. Rev. Sociol. Polit., Curitiba, v. 18, n. 36, p. 15-23, jun. 2010. Disponível em: <http://www.scielo.br/scielo. php?script=sci_arttext\&pid=S0104-44782010000200003\&lng=pt\&nrm=iso $>$. Acesso em: 18 mai. 2016. 
REGO, F. C. V.S. Hipertrofia muscular como tecnologia de gênero na produção de masculinidades entre homens transexuais. In: ENCONTRO ANUAL ANPOCS, 38., 2014, Caxambu/MG. Anais... Caxambu, 2014. Disponível em: <http:// www.anpocs.com/index.php/papers-38-encontro/gt-1/gt33-1/9357-hipertrofiamuscular-como-tecnologia-de-genero-na-producao-de-masculinidades-entrehomens-transexuais/file>. Acesso em: 05 jul. 2018.

RIBEIRO, C. R. S.; SIQUEIRA, V. H. F. de. Construindo a masculinidade hegemônica: acomodaçóes e resistências a partir da apropriação de personagens de novelas por adolescentes das camadas populares. In: REUNIÃO NACIONAL DA ANPED, 28., 2005, Caxambu/MG. Anais... Caxambu, 2005. Disponível em: <http://28reuniao.anped.org.br/?_ga $=1.7852530 .1332736477 .144375319$ 9>. Acesso em: 05 abr. 2016.

RITTI, R. C. de O. Adolescentes violentos? Que discurso é esse? Práticas discursivas e constituição do masculino na periferia. In: REUNIÃO NACIONAL DA ANPED, 35., 2012, Porto de Galinhas. Anais... Porto de Galinhas, 2012. Disponível em: <http://35reuniao.anped.org.br/images/stories/trabalhos/ GT23\%20Trabalhos/GT23-1454_int.pdf>. Acesso em: 05 abr. 2016.

ROLIM, R. C.; RODRIGUES, F. C. M. O assassinato de um homossexual diante de um tribunal da Capital da República em meados do século XX. Revista Estudos Feministas, Florianópolis, v. 21, n. 1, p. 325-342, maio 2013. ISSN 1806-9584. Disponível em: <https://periodicos.ufsc.br/index.php/ref/article/ view/S0104-026X2013000100017/24653>. Acesso em: 17 abr. 2016.

ROSA, R. M. Corporeidades masculinas nômades: o espaço da docência como heterotopia. In: REUNIÁO NACIONAL DA ANPED, 33., 2010, Caxambu/ MG. Anais... Caxambu, 2010. Disponível em: <http://33reuniao.anped.org. br/33encontro/app/webroot/files/file/Trabalhos\%20em\%20PDF/GT23-6642-Int.pdf>. Acesso em: 05 abr. 2016.

SARTOR, A. K. R. A Paternidade na Conciliação Trabalho-Família. In: ENCONTRO ANUAL ANPOCS, 42., 2018, Caxambu/MG. Anais... Caxambu, 2018. Disponível em: <http://www.anpocs.com/index.php/4oencontro-anual-2018/2746-encontros-anuais/39-encontro-anual-da-anpocs-sp417/1878-teste>. Acesso em: 05 jul. 2018.

SILVA, F. A. Masculinidades críticas e a proposição analítica e relacional nas contemporâneas discussōes de gênero. Revista Estudos Feministas, Florianópolis, v. 23, n. 3, p. 1026-1029, nov. 2015. ISSN 18069584. Disponível em: <https://periodicos.ufsc.br/index.php/ref/article/ view/41948/30522>. Acesso em: 17 abr. 2016. 
SILVA JUNIOR, P. M. da; IVENICK, A. Autorrepresentaçóes e subalternidades: famílias, racialidades e masculinidades na escola. In: REUNIÃO NACIONAL DA ANPED, 38., 2017, São Luís/MA. Anais... São Luís, 2017. Disponível em: $<$ http://anais.anped.org.br/sites/default/files/arquivos/trabalho_38anped_2017_ GT23_160.pdf>. Acesso em: 05 abr. 2018.

SILVA, T. T. da. A produção social da identidade e da diferença. In:

(Org.). Identidade e diferença: a perspectiva dos estudos culturais. Petrópolis: Vozes, 2008. p. 73-102.

SILVA, V. C. A. Conciliação trabalho e família: licenças-parentais e paternidade no Brasil e na Espanha. In: ENCONTRO ANUAL ANPOCS, 42., 2018, Caxambu/MG. Anais... Caxambu, 2018. Disponível em: <http://www.anpocs. com/index.php/4o-encontro-anual-2018/2746-encontros-anuais/39-encontroanual-da-anpocs-sp-417/1878-teste>. Acesso em: 05 jul. 2018.

SORJ, B.; DAFLON, V. T.; GRILLO, B. R. S. "Estar presente": a extensão da licença paternidade e a ideologia do "novo pai". In: ENCONTRO ANUAL ANPOCS, 41., 2017, Caxambu/MG. Anais... Caxambu, 2017. Disponível em: <http://www.anpocs.com/index.php/papers-40-encontro-2/gt-30/gt1317/10715-estar-presente-a-extensao-da-licenca-paternidade-e-a-ideologia-donovo-pai/file>. Acesso em: 05 jul. 2018.

SOUSA, I. F. de. Sexualidade e experiências masculinas no mundo da prostituição: permanências e mudanças. In: ENCONTRO ANUAL ANPOCS, 25., 2001, Caxambu/MG. Anais... Caxambu, 2001. Disponível em: <http://www. anpocs.com/index.php/2005-sp-1980582675/1046-encontros-anuais/25oencontro/549-programa-e-resumos>. Acesso em: 05 jul. 2018.

TARNOWSKI, F. "Paternidade gay?": sentidos da masculinidade para homossexuais com filhos. In: Encontro Anual ANPOCS, 25., 2001, Caxambu/ MG. Anais... Caxambu, 2001. Disponível em: <http://www.anpocs.com/ index.php/2005-sp-1980582675/1046-encontros-anuais/25o-encontro/549programa-e-resumos>. Acesso em: 05 jul. 2018.

TEIXEIRA, J. M. Os filhos dos homens: vasectomia e masculinidade como tecnologia pentecostal. In: ENCONTRO ANUAL ANPOCS, 42., 2018, Caxambu/MG. Anais... Caxambu, 2018. Disponível em: <http://www.anpocs. com/index.php/4o-encontro-anual-2018/2746-encontros-anuais/39-encontroanual-da-anpocs-sp-417/1878-teste>. Acesso em: 05 jul. 2018.

VELASCO-MARTÍNEZ, A. "No soy feminista, pero...”: Mitos y creencias de la juventud universitaria sobre el feminismo. $451 \mathrm{f}$. Tesis Doctoral - Universitat 
de Barcelona, Facultad de Educación, Programa de Doctorado "Educación y Sociedad”, 2016.

VERAS, E. F. (Des)Fazendo-se homem. Revista Estudos Feministas, Florianópolis, v. 22, n. 3, p. 999-1001, set. 2014. ISSN 1806-9584. Disponível em: <https://periodicos. ufsc.br/index.php/ref/article/view/36763/28585>. Acesso em: 17 abr. 2016.

WITTMANN, I. Transhomens: masculinidades, políticas e vivências. Revista Estudos Feministas, Florianópolis, v. 24, n. 2, p. 661-663, jun. 2016. ISSN 1806-9584. Disponível em: <https://periodicos.ufsc.br/index.php/ref/article/ view/44616/31766>. Acesso em: 17 abr. 2016.

ZIRBEL, I. Estudos Feministas e Estudos de Gênero no Brasil: um debate. 2007. 212 f. Dissertação (Mestrado em Sociologia Política) - Centro de Filosofia e Ciências Humanas, Universidade Federal de Santa Catarina, Florianópolis. 2007. Disponível em: <https://repositorio.ufsc.br/bitstream/ handle/123456789/90380/241321.pdf?sequence=1>. Acesso em: 02 abr. 2016. 